\title{
Effect of Aggressive Early High-Dose Intravenous Amino Acid Infusion and Early Trophic Enteral Nutrition on Very Low Birth Weight Infants
}

\author{
Man-Yau Ho ${ }^{1,2}$, Yu-Hsuan Yen ${ }^{2,3 *}$, Hsiang-Yin Chen ${ }^{4}$, Shu-Chen Chien ${ }^{4}$, Mao-Chih Hsieh², \\ Yao-Shun Yang ${ }^{1}$ \\ ${ }^{1}$ Department of Pediatrics, Taipei, Chinese Taipei; ${ }^{2}$ Nutritional Support Team, Taipei, Chinese Taipei; ${ }^{3}$ Pharmacy, Taipei Medical \\ University_Wan Fang Hospital, Taipei, Chinese Taipei; ${ }^{4}$ Department of Clinical Pharmacy, Taipei Medical University, Taipei, Chi- \\ nese Taipei. \\ Email: *sandrayen@tmu.edu.tw
}

Received September $9^{\text {th }}, 2012$; revised October $9^{\text {th }}, 2012$; accepted October $16^{\text {th }}, 2012$

\begin{abstract}
Objective: Very-low-birth-weight (VLBW) preterm infants are at risk of growth delay if they do not receive adequate nutritional support. This study evaluated the effect of aggressive early high-dose amino acid infusion plus early enteral trophic feeding on growth in VLBW infants within the first day of life. Study Design: The effect of a high-dose $3 \mathrm{~g}$ amino acid (HAA) $/ \mathrm{kg} / \mathrm{d}$ regimen beginning on the first day of life was compared with that of low-dose amino acid (LAA) supplementation at a dose of 0.5 or $1.0 \mathrm{~g} / \mathrm{kg} / \mathrm{d}$. The primary outcome measures were the days of regained birth weight and achieved full enteral feeding. Result: Compared with the 19 infants in the LAA group, the 17 infants in the HAA group achieved significantly earlier full enteral feeding (7.8 \pm 3.6 vs. $15.2 \pm 8.9, p=0.003$ ) and regained birth weight (13.3 \pm 3.8 vs. $17.5 \pm 7.9, p=0.047)$. In addition, shorter parenteral nutrition time was achieved by HAA administration $(p<0.05)$. Total energy intake was greater during the first 7 days of life in the HAA group (85 \pm 12 $\mathrm{kcal} / \mathrm{kg} / \mathrm{d}$ on day 7) than in the LAA group (60 $\pm 16 \mathrm{kcal} / \mathrm{kg} / \mathrm{d}$ on day $7, p<0.001)$. Other clinical parameters such as length of hospital stay and morbidity favored the use of HAA. Conclusion: Aggressive early simultaneous amino acid administration plus enteral feeding during the first few days of life for preterm infants was associated with improved weight gain and earlier full enteral feeding.
\end{abstract}

Keywords: Early Nutrition; Trophic Enteral Feeding; Very Low Birth Weight; Preterm Infant

\section{Introduction}

Very-low-birth-weight (VLBW) infants are born at a time of rapid intrauterine brain and body growth [1]. These infants have limited endogenous energy stores and depend on administering nutrients in postnatal life. Therefore, rapid establishment of adequate exogenous nutrition is essential. VLBW infants who receive nutrition without a supply of protein may lose as much as $0.5-1.0 \mathrm{~g} / \mathrm{kg} / \mathrm{d}$ of endogenous protein [2]. Insufficient protein or amino acid administration may worsen the respiratory distress syndrome (RDS), cause growth delay, or increase morbidity in VLBW infants [3-7]. It is common practice for preterm infants requiring nutritional support to be gradually started on amino acid infusion between 0 and 36 hours after birth.

Several studies have demonstrated that infusion of amino acids in the first days of life decreases protein

*Corresponding author. break down and maintains a positive energy balance [5-7]. Recent studies have shown that protein administration at a dosage of $3 \mathrm{~g} / \mathrm{kg} / \mathrm{d}$ beginning on day 1 of life is a safe and effective method of improving weight gain and anabolism [8-11]. Despite this information, we found that significant nutrient deficiencies are usually observed in the neonatal intensive care unit in Taiwan and premature infants are frequently discharge at weights less than the 10th percentile and more complications.

This study evaluated the effect of highly first dose amino acid infusion $(3 \mathrm{~g} / \mathrm{kg} / \mathrm{d})$ administered during the first 24 hours of life in VLBW infants and compared it with that of lowly first dose early amino acid infusion $(<1 \mathrm{~g} / \mathrm{kg} / \mathrm{d})$ on growth in VLBW infants.

\section{Methods}

\subsection{Patients}

This study was conducted during the period January 
2006 to December 2010. The study subjects comprised preterm infants with gestational age less than 37 weeks and a birth weight between $501 \mathrm{~g}$ and $2000 \mathrm{~g}$ who required mechanical ventilation for RDS at the neonatal intensive care unit (NICU) at the Taipei Medical University-Wan Fang Hospital. Preterm infants who died within 5 days of birth and those who were born in infection, congenital diseases, or metabolic problems that may affect nutrient metabolism were not included in the study. All preterm infants admitted to the NICU taking care by two pediatric neonatologists. They had the same mode of respiratory care and enteral feeding protocol.

\subsection{Nutrition Administration}

Parenteral nutrition was started through a high position umbilical venous catheter on the first day of life. The umbilical catheter was removed and changed to a percutaneous central venous catheter (PCVC) within 1 week. The preterm infants in the low-dose amino acid (LAA) group were started on amino acids (Aminosteril Infant Fresenius Kabi, Germany) at 0.5 or $1.0 \mathrm{~g} / \mathrm{kg} / \mathrm{d}$ on day 1 , which was increased to a maximum of $2.0 \mathrm{~g} / \mathrm{kg} / \mathrm{d}$ as a maintenance dose. Infants in the high-dose amino acid (HAA) group were started on amino acids 2- or 3.0 $\mathrm{g} / \mathrm{kg} / \mathrm{d}$ on day 1 .

The final glucose concentration of parenteral nutrition was $5 \%$. All infants in this study began to receive breast milk on the first day of life at a continuous rate of 0.5 $\mathrm{mL} / \mathrm{h}$ as controlled by a Terumo pump. The amount of breast milk was advanced gradually as tolerated. Fat emulsions were started no earlier than day 4 in both groups.

All premature infants were given 60 to $80 \mathrm{~mL} / \mathrm{kg} / \mathrm{d}$ of fluid on day 1 , and this amount of fluid was increased daily at increments of $10 \mathrm{~mL} / \mathrm{kg}$ up to $150 \mathrm{~mL} / \mathrm{kg} / \mathrm{d}$ by day 7. Exogenous surfactant was used in 24 RDS infants. The time of surfactant use was similar in both groups.

\subsection{Outcome Measures}

The primary outcome measures were the days to achieve full enteral feeding by breast milk and the days to regain birth weight. The caloric intake in the HAA and LAA groups during the 7-day study period was also collected. Other measures included the number of days on ventila- tion, length of hospital stay, and complications such as patent ductus arteriosus (PDA), intraventricular hemorrhage (IVH), retinopathy of prematurity (ROP), bronchopulmonary dysplasia (BPD), necrotizing enterocolitis (NEC), and bacteremia

\subsection{Statistical Analysis}

Two-sample t-tests were used to measure differences in clinical outcomes between the two groups of infants. The Wilcoxon signed-rank test was used to analyze differences in the measurements without normal distribution. All statistical tests were computed using the statistical package SPSS (Version 13.0, SPSS Inc, Chicago, IL, USA). A $p$ value $<0.05$ was considered to indicate statistical significance.

\section{Results}

A total of 17 preterm infants who received HAA supplementation during the period May 2008 through December 2010 were compared with 19 infants who received LAA supplementation during the period January 2006 through April 2008. One infant in each group died within 5 days due to respiratory failure. There were no significant differences in gestational age, birth weight, gender, 5-minute Apgar score, or mode of delivery between infants in the HAA group and those in the LAA group (Table 1).

Information on nutritional support during the study period is shown in Table 2. As anticipated, the amino acid

Table 1. Demographic data.

\begin{tabular}{ccc}
\hline & HAA ( $=17)$ & LAA ( $\mathrm{n}=19)$ \\
\hline Gestational age (wk) & $31 \pm 1.9$ & $31 \pm 2.2$ \\
Birth weight (g) & $1428 \pm 341$ & $1446 \pm 293$ \\
Gender (male/female) & $11 / 6$ & $9 / 10$ \\
5-minute Apgar score & $8(7-9)$ & $8(7-9)$ \\
Mode of delivery & & \\
NSD & 12 & 15 \\
C/S & 5 & 4 \\
\hline
\end{tabular}

Mean \pm SD. Median (range). HAA, high-dose amino acids; LAA, low-dose amino acids; C/S, cesarean section; NSD, nature spontaneous delivery.

Table 2. Nutritional support in the HAA and LAA group.

\begin{tabular}{lcc}
\hline & HAA (n=17) & LAA (n value \\
\hline Age at introduction of amino acids $(\mathrm{d})$ & $0.58 \pm 0.38$ & $0.49 \pm 0.33$ \\
Age at enteral feeding (d) & $0.19 \pm 0.12$ & $0.19 \pm 0.10$ \\
Amino acid intake in the first day (g/kg/d) & $2.76 \pm 0.43$ & $0.95 \pm 0.25$ \\
Total energy intake, PN + BM, in the first day (kcal/kg/d) & $18.99 \pm 7.11$ & $<.29 \pm 3.04$ \\
\hline
\end{tabular}

Mean \pm SD. ${ }^{\dagger}$ Statistically significant. HAA, high-dose amino acids; LAA, low-dose amino acids; PN, parenteral nutrition; BM, breast milk. 
and energy intakes on the first day were significantly greater in the HAA group than in the LAA group. Total energy intake, including parenteral nutrition and enteral feeding by breast milk during the first 7 days of life, was consistently greater in the HAA group $(85 \pm 12 \mathrm{kcal} / \mathrm{kg} / \mathrm{d}$ on day 7) than in the LAA group (60 $\pm 16 \mathrm{kcal} / \mathrm{kg} / \mathrm{d}$ on day 7) (Figure 1). The total calories in preterm infants can reach $80 \mathrm{kcal} / \mathrm{kg} / \mathrm{d}$ on the sixth day in the HAA group and on the eighth in the LAA group (Figure 1). Therefore, no fat emulsions were given. The mean number of days of parenteral nutrition in the HAA group was significantly less than that in LAA group, resulting in a significant reduction in medical care costs $(9.5 \pm 4.2$ versus $16.1 \pm 12.6, p=0.042$ ). Infants in the LAA group required almost 2 times of day to reach enteral nutrition of $80 \mathrm{kcal} / \mathrm{kg} / \mathrm{d}$ compared to infants in the HAA group $(15.2 \pm 8.9$ versus $7.8 \pm 3.6, p=0.003)$. Infants in the HAA group regained their birth weight sooner than infants in the LAA group. The HAA group infants required fewer days of parenteral nutrition. Although there was no significant difference, infants in the LAA group tended to need mechanical ventilation for longer periods and required longer hospitalization stays than patients in the HAA group (Table 3). There were no differences in rates of morbidity (bacteremia, PDA, IVH, NEC, ROP, and $\mathrm{BPD}$ ) between the two groups (Table 4).

\section{Discussions}

Early administration of amino acids has been shown to be safe and effective at establishing nitrogen balance in preterm infants $[9,10]$. In our study, we demonstrated that aggressive early introduction of intravenous highdose amino acids to premature infants with RDS resulted in a significantly earlier achievement of full enteral feeding and birth weight regain without resulting in an increased incidence of complications or adverse side effects. No statistical differences in incidence of bactere-

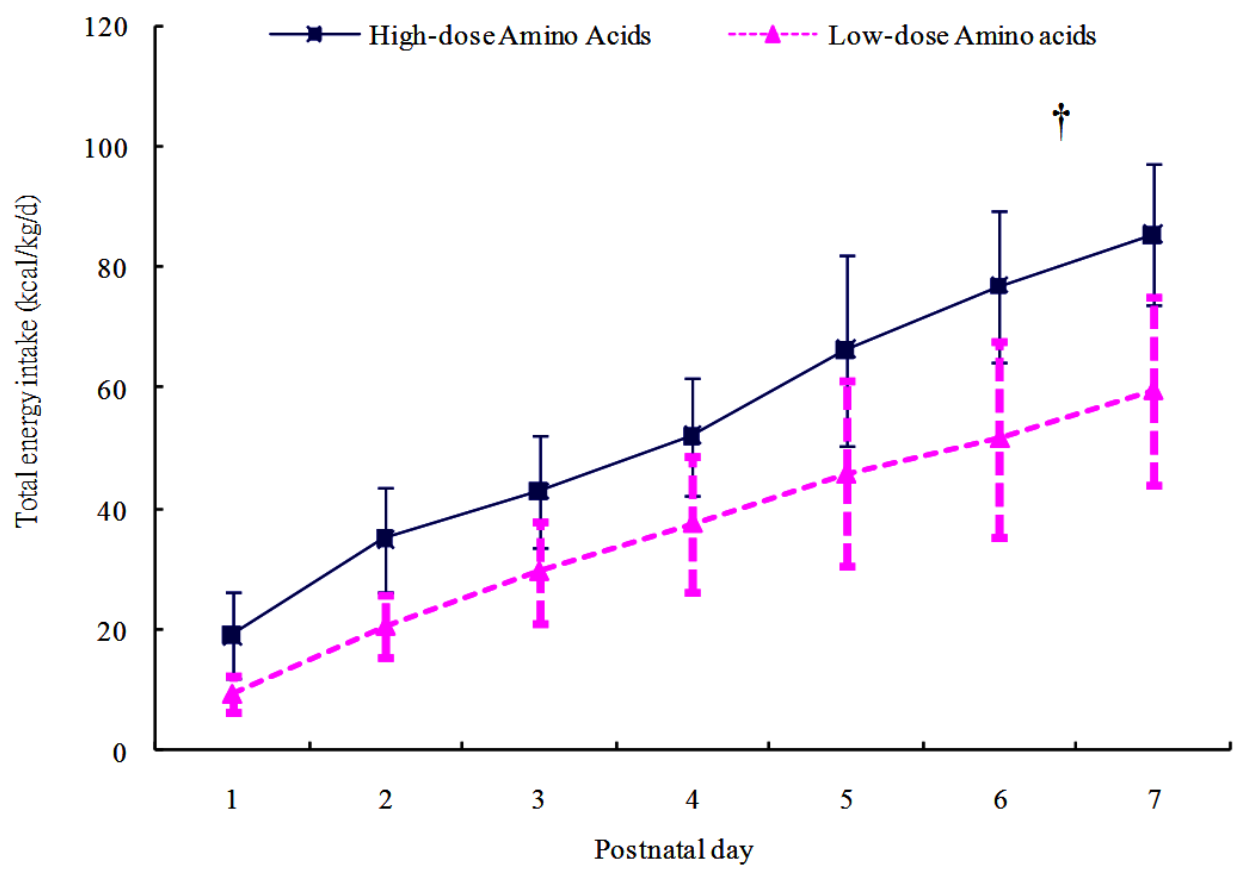

Figure 1. Total energy intake (parenteral and enteral) during the first postnatal week. ${ }^{\dagger}$ Statistically significant.

Table 3. Outcome in the HAA and LAA groups.

\begin{tabular}{lccc}
\hline & HAA (n=17) & LAA (n=19) & $p$ value \\
\hline Duration of parenteral nutrition (d) & $9.5 \pm 4.2$ & $16.1 \pm 12.6$ & $0.042^{\dagger}$ \\
Time to reach minimal enteral energy uptake of $80 \mathrm{kcal} / \mathrm{kg} / \mathrm{d}$ (d) & $7.8 \pm 3.6$ & $15.2 \pm 8.9$ & $0.003^{\dagger}$ \\
Regain birth weight (d) & $13.3 \pm 3.8$ & $17.5 \pm 7.9$ & $0.047^{\dagger}$ \\
$\mathrm{O}_{2}$ exposure (d) & $9.0 \pm 9.5$ & $10.9 \pm 15.1$ & 0.659 \\
Hospital stay required (d) & $38 \pm 17$ & $47 \pm 21$ & 0.187 \\
\hline
\end{tabular}

Mean \pm SD. ${ }^{\dagger}$ Statistically significant. HAA, high-dose amino acids; LAA, low-dose amino acids. 
Table 4. Morbidities in the HAA and LAA groups.

\begin{tabular}{cccc}
\hline & HAA $(\mathrm{n}=17)$ & LAA $(\mathrm{n}=19)$ & $p$ value \\
\hline Complications & & 4 & 0.207 \\
Bacteremia & 1 & 6 & \\
PDA & 4 & 3 & \\
IVH & 1 & 0 & \\
NEC & 0 & 0 & \\
ROP & 0 & 0 \\
BPD & 0 &
\end{tabular}

HAA, high-dose amino acids; LAA, low-dose amino acids; PDA, patent ductus arteriosus; IVH, intraventricular hemorrhage; NEC, necrotizing enterocolitis; ROP, retinopathy of prematurity; BPD, brochopulmonary dysplasia.

mia, PDA, IVH, NEC, ROP, or BPD and no differences in length of hospital stay were found between the HAA and LAA groups.

Early provision of amino acids stimulates whole-body protein synthesis and also depressing protein breakdown [12]. All infants in the HAA group reached full enteral feeding by the eighth day, which was much faster than the rate reported in previous studies. It has been reported that VLBW infants require a daily minimum of 60 $\mathrm{kcal} / \mathrm{kg} / \mathrm{d}$ (including $2.5 \mathrm{~g} / \mathrm{kg} / \mathrm{d}$ of AA) to minimize catabolism, and 80 to $90 \mathrm{kcal} / \mathrm{kg} / \mathrm{d}$ (including 2.7 to 3.5 $\mathrm{g} / \mathrm{kg} / \mathrm{d}$ of AA) to maintain the rate of growth $[13,14]$. Preterm infants should receive nutrition similar to that in their intrauterine life. When parenteral amino acids and breast milk feeding are started within the first 48 hours of life, full enteral feeding (minimal breast milk intakes of $80 \mathrm{kcal} / \mathrm{kg} / \mathrm{d}$ ) can be reached by 36 days. Studies have shown that full enteral feeing may be achieved by 13 days if parenteral nutrition and enteral nutrition are started simultaneously on the first day of life We have found that starting high dose amino acid support (2- or $3.0 \mathrm{~g} / \mathrm{kg} / \mathrm{d}$ ) in conjunction with breast milk on the first day of life can significantly shorten the time to achieve full enteral feeding. Some clinicians concern about early use of high dose protein increased in blood urea nitrogen (BUN) and cholestasis. However, previous study from Ridout et al. showed no relationship between BUN and amino acid intake [15]. Jadhav looked at the relationship between metabolic acidosis and amino acid intake but did not find a correlation [16]. There is no scientific reason to explain why VLBW infants should not be offered 3 to $3.5 \mathrm{~g} / \mathrm{kg} / \mathrm{d}$ of amino acids immediately after birth. In this study, all infants in the HAA group reached full enteral feeding by the eighth day.

Deaths in preterm infants after receiving infusion of intravenous fat emulsions have been reported in the medical literature. Autopsy findings included intravascu- lar fat accumulation in the lungs [17]. Treatment of premature and low birth weight infants with intravenous fat emulsion must be based upon careful benefit-risk assessment. We find that either group infants can be reached full enteral feeding on the first week. Therefore, no fat emulsions were given.

Weight gain can be difficult to obtain because prematurity and RDS may interfere with energy uptake. A previous study demonstrated that early administration of 0.5 to $1 \mathrm{~g} / \mathrm{kg} / \mathrm{d}$ amino acid supplementation and enteral feeding was beneficial for premature infants to gain weight by 2 weeks [7]. Our study showed that VLBW infants who received aggressive early amino acid therapy regained their birth weight 5 days sooner than infants who only received low dose amino acid supplementation. Amino acid infusion not only helps to shorten the time to reach full enteral nutrition and birth weight regaining, but also improves respiratory function and reduces apnea in preterm infants [18]. Although the time required for mechanical ventilation depends on the severity of RDS and the early use of exogenous surfactants, good nutrition is also one of the important factors influencing infant respiratory function. The current study did not find differences in the use of mechanical ventilation between high or low dose amino acid infusions. However, our previous study showed that simultaneous low dose amino acid infusion and breast milk feeding resulted in a shorter duration of mechanical ventilation in premature infants with RDS [7]. Early nutrition particularly with sufficient branched-chain amino acids improves respiratory muscle strength, thus shortening the time of mechanical ventilation.

This retrospective study demonstrated that aggressive early simultaneous amino acid administration with breast milk feeding was associated with improved weight gain and earlier achievement of full enteral feeding in preterm infants. Because of the small sample size, further research is needed to strengthen our idea.

\section{REFERENCES}

[1] E. E. Ziegler, A. M. O’Donnell and S. E. Nelson, "Body Composition of the Reference Fetus," Growth, Vol. 40, No. 4, 1976, pp. 329-341.

[2] D. H. Adamkin, "Issues in the Nutritional Support of the Ventilated Baby,” Clinics in Perinatology, Vol. 25, No. 1, 1998, pp. 79-96.

[3] D. I. Shulman and K. Kanarek, "Gastric, Motilin, Insulin, and Insulin-Like Growth Factor-I Concentrations in VeryLow-Birth-Weight Infants Receiving Enteral or Parenteral Nutrition,” Journal of Parenteral and Enteral Nutrition, Vol. 17, No. 2, 1993, pp. 130-133. doi:10.1177/0148607193017002130

[4] J. B. Van Goudoever, C. J. Wattimena and T. Colen, “Im- 
mediate Commencement of Amino Acid Supplement in Preterm Infants: Effect on Serum Amino Acid Concentration and Protein Kinetics on First Day of Life,” The Journal of Pediatrics, Vol. 127, No. 3, 1995, pp. 458-465. doi:10.1016/S0022-3476(95)70083-8

[5] J. Saini, P. Macmahon and J. B. Morgan, "Early Parenteral Feeding of Amino Acids," Archives of Disease in Childhood, Vol. 64, 1989, pp. 1362-1366. doi:10.1136/adc.64.10 Spec No.1362

[6] K. G. Brownlee, E. J. Kelly and P. C. Ng, "Early or Late Parenteral Nutrition for the Sick Preterm Infant?" Archives of Disease in Childhood, Vol. 69, 1993, pp. 281-3. doi:10.1136/adc.69.3_Spec_No.281

[7] M. Y. Ho, Y. H. Yen and M. C. Hsieh, "Early versus Late Nutrition Support in Premature Neonates with Respiratory Distress Syndrome,” Nutrition, Vol. 19, No. 3, 2003, pp. 257-260. doi:10.1016/S0899-9007(02)01110-3

[8] P. J. Thureen, D. Melara and P. V. Fennessey, "Effect of Low versus High Intravenous Amino Acid Intake on Very Low Birth Weight Infants in the Early Neonatal Period,” Pediatric Research, Vol. 53, No. 1, 2003, pp. 24-32. doi:10.1203/00006450-200301000-00008

[9] H. M. Ibrahim, M. A. Jeroudi and R. J. Baier, “Aggressive Early Total Parenteral Nutrition in Low-BirthWeight Infants,” The Journal of Pediatrics, Vol. 24, No. 8, 2004, pp. 482-486. doi:10.1038/sj.jp.7211114

[10] W. J. Frans, M. S. Braake and H. P. Chris, "Amino Acid Administration to Premature Infants Directly after Birth," The Journal of Pediatrics, Vol. 147, No. 4, 2005, pp. 457-461.

[11] C. J. Valentine, S. Fernandez and L. K. Rogers, "Early Amino-Acid Administration Improves Preterm Infant Weight," The Journal of Pediatrics, Vol. 29, 2009, pp.
428-432. doi:10.1038/jp.2009.51

[12] S. C. Denne, "Regulation of Proteolysis and Optimal Protein Accretion in Extremely Premature Newborns," The American Journal of Clinical Nutrition, Vol. 85, Suppl. 2, 2007, pp. 621S-624S.

[13] T. L. Anderson, C. R. Muttart and M. A. Bieber, "A Controlled Trial of Glucose vs Glucose and Amino Acids in Premature Infants,” The Journal of Pediatrics, Vol. 94, No. 6, 1979, pp. 947-951. doi:10.1016/S0022-3476(79)80230-9

[14] S. H. Zlotkin, H. M. Brya and G. H. Andeson, "Intravenous Nitrogen and Energy Intakes Required to Duplicate in Utero Nitrogen Accretion in Prematurely Born Human Infanfts,” The Journal of Pediatrics, Vol. 99, No. 1, 1981, pp. 115-120. doi:10.1016/S0022-3476(81)80975-4

[15] E. Ridout, D. Melara and B. Rottinghaus, "Blood Urea Nitrogen Concentration as a Marker of Amino Acid Intolerance in Neonates with Birthweights Less than 1250 g," The Journal of Pediatrics, Vol. 25, No. 2, 2005, pp. 130-133. doi:10.1038/sj.jp.7211215

[16] P. Jadhav, P. S. Parimi, S. C. Kalhan, "Parenteral Amino Acid and Metabolic Acidosis in Premature Infants,” Journal of Parenteral and Enteral Nutrition, Vol. 31, No. 4, 2007, pp. 278-283. doi:10.1177/0148607107031004278

[17] M. Levene, J. S. Wigglesworth and R. Desai, "Pulmonary Fat Accumulation after Intralipid Infusion in the Preterm Infants,” Lancet, Vol. 316, No. 8199, 1980, pp. 815-819. doi:10.1016/S0140-6736(80)90170-1

[18] S. Blazer, G. T. Reinersman, J. Askanazi, "BranchedChain Amino Acids and Respiratory Pattern and Function in the Neonate,” The Journal of Pediatrics, Vol. 14, No. 4, 1994, pp. 290-295. 